\title{
Coupling Engineering and Entrepreneurship Education through Formula SAE
}

\author{
Martin Morris, Fred Fry \\ Bradley University
}

\begin{abstract}
Teams of mechanical engineering students design, build, and race a Formula SAE car as their senior project assignment. Upon completion, the car is entered in a national competition. The overall task is to create a prototype racecar and to develop a business strategy capable of building four production cars per day. A team of entrepreneurship students simultaneously had the assignment to create a business plan that could be used to solicit funding for developing a new business based on manufacturing these cars. An important result of the project is that both the engineering and the entrepreneurship students developed an understanding of both the technical and business challenges of starting a new company. This required development of effective cross-disciplinary communication skills and learning to function in a setting similar to one that might be found in a manufacturing industry.
\end{abstract}

Introduction

Combining engineering teams with entrepreneurship teams is an innovative method of entrepreneurship education. It provides a more realistic environment for developing business plans and exposes both engineers and business students to the language and decision processes faced by many actual companies. Audet, Pegna, and Garon ${ }^{1}$ reported on one such cooperative relationship which engineering and commerce students teamed to develop new products. This paper reports on a project in which entrepreneurship student team built a business plan based around a race car built for Formula SAE competition by engineering students.

Formula SAE is an inter-collegiate competition sponsored by the Society of Automotive Engineers (SAE) in which college teams build and race formula-style racecars. The stated objective of the Formula SAE competition is to "conceive, design, fabricate, and compete with small formula-style racing cars." 2 The students are to assume that a manufacturing firm such as Ford has engaged them to produce a prototype car for evaluation as a production item. The intended customer for this product is non-professional auto-cross racers such as Sport Car Club of America (SCCA) racers. The car is expected to be affordable, reliable, and easy to maintain while providing high performance to the buyer. The car should be comfortable and possess the aesthetics of a formula-type racecar. The premise of the competition is that the manufacturer will produce four cars per day for a limited production run. The prototype vehicle should cost less than $\$ 30,000$. 
At the competition, the cars are judged in both static and dynamic events. The static events include the presentation of a business plan, an engineering design, and a cost analysis. The dynamic events include an acceleration run, a skid-pad test, an auto-cross, a measure of fuel economy, and an endurance race. The points scored in each of these events are totaled and the teams are ranked in order of the total points.

The SAE provides detailed engineering vehicle requirements to provide a fair and safe competition. Each team's compliance with these regulations is certified at the start of the competition. An engineering design report and presentation is judged and scored to reflect the engineering details of the car design. A detailed cost report and presentation is scored to reflect the cost of the prototype and the anticipated cost of the production vehicle. The final static event is a presentation that is intended to convince a manufacturer that this concept is a profitable business venture. The presentation event provides the opportunity for developing a multidisciplinary team that includes engineering, marketing, and entrepreneurship students.

\section{Mechanical Engineering Senior Projects}

Arguably the most important single course in the mechanical engineering curriculum at Bradley University is the capstone senior design project. The project spans both the fall and spring semesters of the senior year and draws heavily on the technical expertise developed in other courses. The objective of the course sequence is to provide a realistic experience in the practice of mechanical engineering design. Senior students are placed on teams of three or four to work as project engineers under the guidance of a faculty advisor. Each team must satisfy the needs their client and ultimately deliver an engineering solution by the end of the academic year. In the case of the Formula SAE project, three engineering teams must collaborate to must deliver a racecar ready for competition. Grading in the course sequence is based on three written reports, three oral reports, and peer evaluations.

Three mechanical engineering teams are typically assigned to the Formula SAE project. The responsibilities of the three teams have been divided into three overlapping domains: 1) engine and drive train, 2) suspension and controls, and 3) frame and ergonomics. Each team identifies a member as a leader and all three teams select one of the leaders to be the project coordinator. Each of the three teams must develop a plan and budget that accomplishes the objective of their part of the car while satisfying the requirements of the other two teams. The project coordinator assumes the additional responsibility of integrating the team schedules and budgets into a coordinated plan.

\section{Entrepreneurship Course Project}

The entrepreneurship course is taught each spring semester and is open to upper level business students. Grading in the course consists of two exams, class discussion, and a business plan project. The business plan project comprises forty percent of the total grade in the course. Students are allowed to choose their own teams and also develop a business plan for a potential business of their choice. Students are encouraged to develop a plan for a business that one or more team members would actually like to start, rather than a plan for a typical student-oriented 
business such as a bar, a shuttle service, or a used-book store. Nevertheless, history shows that many of the projects end up being hypothetical businesses with little realism involved.

In the 2000 spring semester, student teams were offered the opportunity to work with the Mechanical Engineering students in developing the business plan for the SAE Formula Car project. One entrepreneurship team volunteered to work with the engineering students. This entrepreneur team met with the project teams from engineering weekly to request and exchange the data needed for the financial aspects of the business plan. Entrepreneurship students also made use of information about these cars that a team of marketing students had assembled in a class project the preceding semester. At the end of the spring semester, the entrepreneurship students present their business plan to their class peers and the engineering team leaders.

The Need for Collaboration

The need for collaboration between engineering students and entrepreneurship students was evident at the outset of the spring semester. The engineering project teams needed to include a business plan as part of a static event that was part of the SAE competition. However, engineering students had few, if any, business courses and no knowledge of how to build a business plan, project costs, or create a marketing strategy. The business students, on the other hand, had virtually no knowledge of engineering and certainly little knowledge of the processes necessary to design and manufacture a limited production racecar. Yet these same requirements, reflect an environment found throughout industry in which both the engineering and business students will have to work and hopefully succeed in the future.

The requirements of the two courses - senior project for the mechanical engineers and the business plan for the entrepreneurship students - demanded that the two groups interact closely in order to develop and share information that the teams could use to build a business plan. They also required that the students from two different disciplines learn to communicate in a language that both could understand. For example, the entrepreneurship students needed as a minimum the information shown in Table 1 in order to complete the financial aspects of the plan.

Table 1

Information Required From Engineering Team for the Business Plan

- Total number of cars to be produced

- Fixed costs

- Variable costs

- Size of facility needed

- Lease or purchase of facility (lease recommended)

- Portions of the project to be out-sourced

- Target market that would buy the cars

- Size of the target market

- Desired price to be charged

- Optimal method of reaching the target market

- Price elasticity of the demand for the cars 
However, few of these topics have a direct effect on the actual engineering planning, design or fabrication of the prototype vehicle and some of these concepts were unknown to the engineering students. These are topics that have not been regularly included in most technical mechanical engineering courses. Yet, these are topics that could easily be included as part of the ABET 2000 criterion. This type of cross-discipline teaming is also suggested as an important part of accreditation.

\section{Cross-Disciplinary Team Structure}

The engineering teams consisted of a frame and ergonomics team, a suspension and controls team, and an engine and drive train team. Each engineering team chose a team leader. Then an overall project manager was chosen from these team leaders. The entrepreneurship team consisted entirely of business management majors with an informal leader arising from the group. Marketing students had worked with the engineering teams in earlier semesters. The students were organized semi-formally into a structure shown in Figure 1. The overall project manager from the engineering teams was responsible for integrating the efforts of all of the teams and facilitating interactions.

Figure 1: Bradley Formula SAE Team Organization

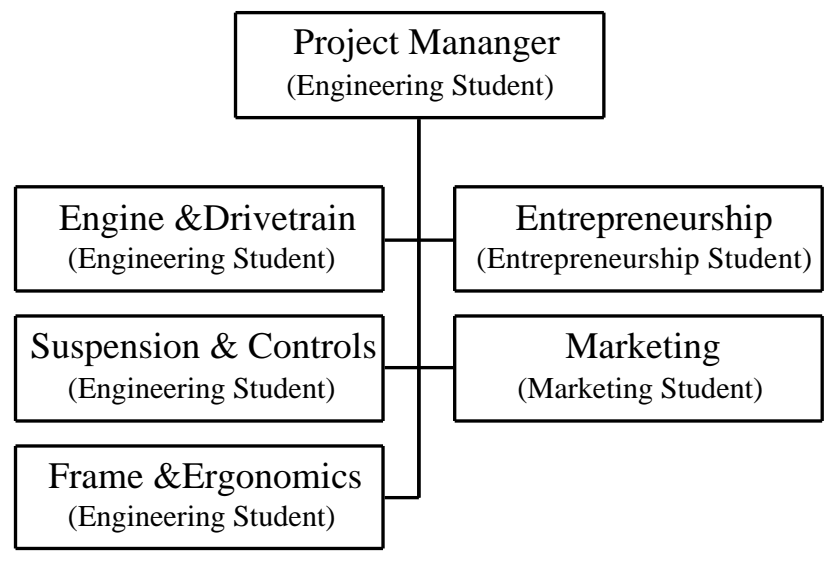

In a real start-up business, business experts would probably be responsible for managing the project, directing a business strategy, and integrating the efforts of the teams. However, the chronology of the business and engineering courses prevented this arrangement. Yet, the entrepreneurship team had to make a number of decisions as part of their course requirements. These included the form of the business, the management structure of the company, the number of employees required to manufacturing the production cars, the amount of financing needed, the type of financing used, the best method of marketing the car. This information was informally reported to the engineering students as part of the weekly meeting exchange. However, unlike an actual business environment, the decisions by the business students had little real effect on the design of the vehicle. 
Results

There were several categories of results from the projects as discussed below. First are the results in terms of the business plan and the analysis that preceded it. Second, results derived from the competition itself. Lastly, we discuss the results in terms of the benefits gained by the student teams.

Results - Business Plan

The business plan showed total capital required to make four cars per day was $\$ 1,000,000$ with $\$ 750,000$ recommended to be raised by selling seventy-five shares at $\$ 1000$ each. The remaining $\$ 250,000$ would be raised through debt financing. First year marketing expenses were to be $\$ 114,500$ with most of the expense going to magazines typically read by amateur racers. The price for the car was determined to be $\$ 12,000$ with COGS of $\$ 8,500$, giving a gross margin of $\$ 3,500$ per unit. Break-even was projected for the seventh month.

The form of business was determined to be a Subchapter S Corporation which provided the best options for raising equity while limiting the liability of the owners and allowing pass through to investor's IRS 1040s. The management structure for the proposed company is shown in Figure 2. A total of 60 employees would be needed to produce the number of cars indicated.

Figure 2: Company Management Structure

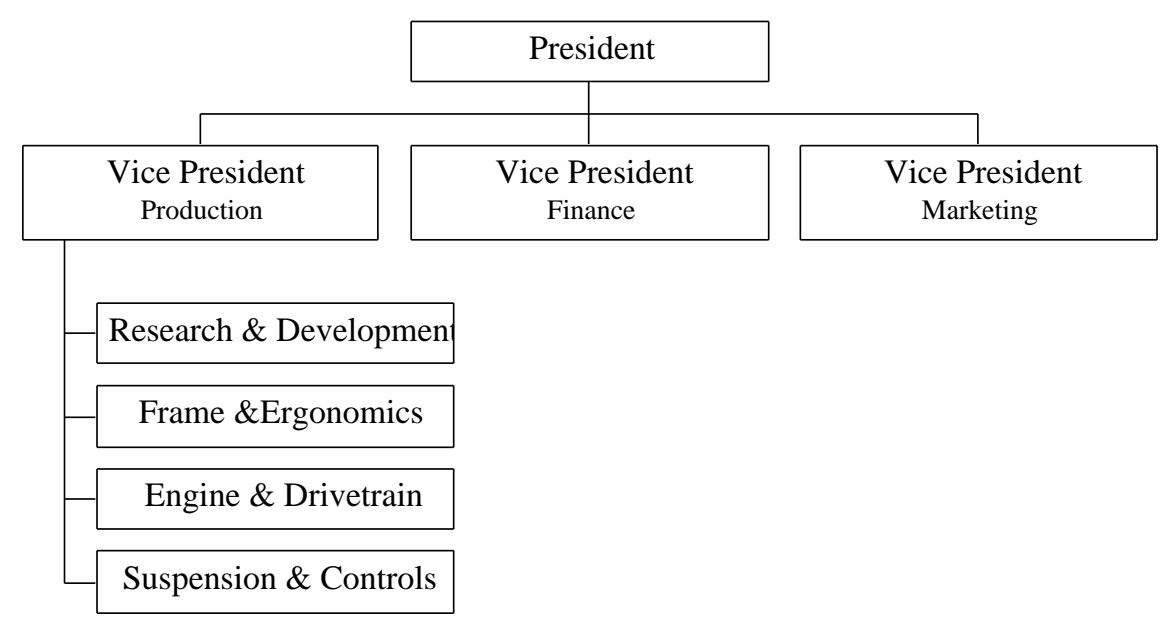

Results - Competition

One member of the entrepreneurship team traveled to Detroit with the engineering team to participate in the competition. The entrepreneur student and one engineering student jointly delivered a multi-media presentation to SAE judges in one of the static events. The presentation highlighted the features of the car and details of the business plan. In preparation for the competition, the students were advised to prepare the presentation as if they were selling their concept to a group of venture capitalists. The team placed 14th out of 104 teams competing which was considered good given that it was the first time a business plan had been included. 
Nearly all of the questions from the judges after the presentation focused on the business plan. After the questions, the judges enthusiastically endorsed the cross-disciplinary teaming and encouraged future collaboration. Written feedback from the judges included comments such as "Excellent tie-in between business and technical aspects." "Good mix between marketing and engineering." and "Market research was good." The most significant criticism was related to manufacturing and design issues rather than business plan issues.

Results - Benefits

The SAE Formula Car project had significant benefits for both the engineers and entrepreneurship students. First each team was exposed to knowledge and concepts that they had not experienced before. The engineers, for example, began to recognize the impact of business decisions on an engineering project and that these decisions are often made by non-engineers. They learned the importance of determining costs while designing a product and were constantly reminded that the purpose of their engineering activities were to satisfy the needs of the marketplace. The business students began to learn the language used by engineers and technicians in production and design processes and learned to be sympathetic to the needs and requirements of technical disciplines. Both teams learned the challenges and the value of coordination regarding information exchange, cost analysis, lead times, and projecting net income.

\section{Discussion and Recommendations}

The overall benefit of the joint engineering/entrepreneurship project was to bring realism into both entrepreneurship education and mechanical engineering education. The project gave the business students an experience very close to an actual startup situation. Yet they were able to make decisions and receive feedback in the arena of an academic setting. The engineers received an excellent exposure to the needs and requirements of realistic business environment. As the semester progressed, each group became sensitive to the needs of the other and early animosity changed to collaboration. Attitudes of team members moved from a "Why are we doing this?" by both sets of teams early in the semester to a "How can we help each other?" later in the term.

A number of challenges were encountered as part of this initial teaming arrangement. The two departments that were offering these courses are in separate colleges within the university, with different reporting structures and different levels of encouragement and reward. The authors voluntarily, and informally, created and managed the combined project assuming any additional load. Thus, the only incentive for inter-departmental cooperation was the mutual desire for a more realistic project for both the engineering and entrepreneurship students.

Because of the informal structure, success could be defined differently by the two departments and their students. Entrepreneurship students, being involved only for part of one semester, could define success as achieving a good grade on a written and oral business plan. The goal for the entrepreneurship professor was to provide the students with a nearly real business opportunity upon which to build a business plan and to build enthusiasm beyond a simple graded project. The principle goals of the engineering students were to earn a good grade and perform 
well in the competition at the end of the year. The goal of the engineering professor was to provide the students with a thorough design experience where student teams must develop a design from the initial concept stage to build and deliver a prototype. In an actual company, business and engineering teams work together in a formal structure. The teams have common goals and leadership. The informal cooperation and differences in goals makes total integration of teams difficult.

The sequencing of the courses also provides an obstacle to closer integration. The mechanical engineering senior project is a year-long (two semesters) project while the entrepreneurship business plan requires one semester. Interaction between the groups could be more effective if entrepreneurship students could be identified early and linked to the project in the fall semester. This linkage would allow the business students to provide input to the engineering students earlier in the design cycle, which could potentially lead to modifications in the end design.

Since each department and each course had its own grading system, cross-grading could not be achieved. Thus, the actions of one discipline's team could not be allowed to affect the other teams' grades. If the grades were linked across disciplines, the students would likely be more motivated to work together for a common success and the project would better simulate a project in an industry setting.

Finally, communication was initially very difficult between the two groups. Both engineering and business have their own vernacular. The entrepreneurship students at first understood little of what the engineering teams were reporting at their weekly meetings. Likewise, the engineering students had no understanding of forms of business ownership, market research, or other business concepts. The engineering students could not understand the need for the data required by the business students and as a result were not strongly motivated to gather the data. One of the significant outcomes from the cross-discipline collaboration was that both teams were closer to understanding the needs, requirements. and significance of the other discipline.

\section{Opportunities}

A number of opportunities exist for improving the cooperative project. For example, one or more lectures by business faculty could be given to the engineering teams in the fall semester. This would give the engineering teams an opportunity to collect information needed for the business plan as they work through the fall semester. A table or spreadsheet could be provided for the engineering students to use in recording costs during the fall semester. Provided entrepreneurship students can be identified early, a complementary lecture by the engineering faculty would help the entrepreneur students to understand the purpose and sequence of a design process. This would also help to develop enthusiasm, as well as, an awareness of and sensitivity to the engineering student needs.

Student log books could be completed by both the entrepreneurship and engineering teams, including actions taken, attitudinal assessments, conflict, and understanding levels. This would assist students in analyzing their own and their counterpart's thought processes and actions. This could also lead to improvements in future collaborations. 
In the longer run, other improvements can also be incorporated. The long-term plan is to define a virtual company, similar to the one proposed in the business plan. This virtual company would have an internal structure based upon the three engineering project teams but would have leadership from a business team. It would have a formal business structure including a president (a business student) who answers to a board of directors. The board of directors could consist of the faculty from engineering and business plus four to six shareholders. The shareholders would be the donors that fund the project. The president will interact with the board of directors and will communicate with both the business-related functional areas and the engineering teams. The advantage of this virtual company is that it forces engineering students to communicate their ideas to a non-engineer in a decision making position, much like actual companies operate in industry. The success of the engineering teams would be linked to their understanding of business requirements and their ability to communicate engineering ideas to non-engineers. Similarly, the president of the company would be accountable to the board of directors for the success of the company. The success of the president and the employees would be directly linked to the success of the virtual company.

Feedback from students who have participated in this collaboration has been very positive. Students who now hold positions in industry as practicing professionals have stated that this cross-disciplinary experience has already provided them with an advantage in their current job. They recognize that as engineers they are responsible for including the company's business plan in their engineering design. We intend to use student feedback to make this activity even more realistic.

Bibliography

1. Josee Audet, Joseph Pegna, and Richard Garon, "Joing Engineering and Commerce Business Plan Project: Description and Evaluation," USASBE/SBIDA 2000: The Entrepreneurial Millennium, February 16-20,2000, pp. 16-21.

2. "2001 Formula SAE Rules and Regulations", 2000 Society of Automotive Engineers, Inc., URL:http://www.sae.org/students/2001formrules.pdf

\section{MARTIN MORRIS}

Martin Morris is an Associate Professor of Mechanical Engineering in the College of Engineering and Technology at Bradley University. Dr. Morris received a B.S. and M.S. degree in Mechanical Engineering from the Bradley University in 1977 and 1979, respectively. He received a Ph.D. in Mechanical Engineering from the University of Illinois at Urbana-Champaign in 1987. He was employed at McDonnell Douglas from 1987 to 1997.

\section{FRED FRY}

Fred Fry is a Professor of Business Management and Administration in the Foster College of Business Administration at Bradley University. Dr. Fry received a B.S. and M.B.A. from Oklahoma State University. He received a $\mathrm{Ph} . \mathrm{D}$. from Oklahoma State University in 1976. 